\title{
METODOLOGIA PARA CRIAÇÃO DE ATLAS DE SOLDAGEM DE AÇO BLAR BAINÍTICO MICROLIGADO AO NIÓBIO*
}

\author{
Thiago de Souza Amaral ${ }^{1}$ \\ Marcelo Carboneri Carboni ${ }^{2}$ \\ Américo Scotti ${ }^{3}$
}

\begin{abstract}
Resumo
Os aços de alta resistência microligados ao nióbio têm mostrado ser uma boa opção para fabricação de perfis estruturais, utilizando os conceitos já desenvolvidos para a indústria de gás e óleo. Entretanto, a definição das reais necessidades em termos de soldagem desta família de aços não está bem descrita nas normas de soldagem mais utilizadas pelo setor. Este trabalho demonstra uma metodologia de avaliação destes aços, através de simulações térmicas físicas (Gleeble e dilatometria) e ensaios mecânicos de amostras simuladas, de forma a elaborar um atlas de soldagem orientativo para melhor definição das faixas de parâmetros para soldagem deste material. A metodologia proposta foi aplicada a um aço BLAR bainítico da classe 65 ksi. Foi possível determinar com mais segurança a faixa de energia de soldagem recomendada, inclusive quanto à necessidade ou não do uso de pré-aquecimento, e evidenciar que as simulações são comparáveis a soldas reais. Esta abordagem mostrou trazer benefícios, como redução de custos com processo de pré-aquecimento desnecessário.
\end{abstract}

Palavras-chave: Aço BLAR; Nióbio; Simulação térmica; Soldagem; Otimização de processo.

\section{METHODOLOGY TO CREATE A WELDING ATLAS OF BAINITIC HSLA STEEL NIOBIUM MICROALLOYED}

\section{Abstract}

Niobium microalloyed steels have been shown to be an excellent solution for the fabrication of structural beams, employing concepts developed for the oil and gas industry. However, the definition of the real welding needs of this family of bainite steels is not well described in the welding specifications most commonly used in the construction sector. This paper demonstrates an evaluation methodology for these steels using thermal simulations to develop a welding atlas to better define welding process requirements. The methodology was applied in a HSLA bainitic steel class 65 $\mathrm{ksi}$. It was possible to determine with more accuracy the recommended energy range of the weld, including the need or not of preheating, and show that they were comparable with teal welds. The methodology shows benefits include cost savings resulting from the elimination of unnecessary preheating.

Keywords: HSLA Steel; Niobium; Thermal simulation; Welding; Process optimization.

1 Engenheiro Eletricista, Mestre em Engenharia Mecânica, Engenheiro da Qualidade na CBMM, Araxá, MG, Brasil.

2 Engenheiro Metalurgista, Mestre em Engenharia Metalúrgica, Gerente de Desenvolvimento de Mercado na CBMM, São Paulo, SP, Brasil.

3 Engenheiro Mecânico, PhD em Tecnologia da Soldagem, Professor visitante na UFU, Uberlândia, MG, Brasil, e na University West, Trollhättan, Suécia. 


\section{INTRODUÇÃO}

Uma nova geração de aços estruturais de baixa liga e alta resistência (BLAR) e aços para tubulações produzidos por conformação termomecânica (TMCP) já estão disponíveis[1, 2]. Esses aços, que foram inicialmente desenvolvidos para atender as necessidades das indústrias de petróleo e gás, apresentam aumento de aplicação em outras estruturas. Eles são caracterizados por apresentar alta resistência à tração e tenacidade, conjuntamente com baixo carbono equivalente. Assim, custos de construção podem ficar mais baixo, pois menores espessuras são requeridas no projeto (menores custos com o transporte e montagem e menos tempo e volume de soldagem). Devido ao baixo carbono equivalente, essa nova geração de aços demanda requisitos menores em termos de temperatura de pré-aquecimento e interpasse durante a soldagem, além de melhorar sua conformabilidade, estando em linha com a tendência de redução de custos.

Entretanto, Lan et al. [3] citam que o excelente balanço entre resistência à tração e tenacidade obtidos com os aços de laminação controlada podem ser perturbados pelos ciclos térmicos de soldagem, que se caracterizam por rápido aquecimento, alto pico de temperatura e resfriamento descontrolado. A variação de microestrutura na zona afetada pelo calor (ZAC) pode produzir regiões (subzonas) com baixa tenacidade local, como, por exemplo, nas regiões de grãos grosseiros e intercrítica da ZAC. Ainda, segundo Lan et al. [3], a propriedade destas regiões tem se deteriorado mais nitidamente com a aplicação de procedimentos de soldagem com elevada energia imposta em aços bainíticos convencionais de alta resistência.

Assim, para o aproveitamento completo dos benefícios associados à utilização de aços de nova geração, é necessário desenvolver procedimentos de soldagem adequados e que garantam que todas as regiões das juntas (metal de base, zona afetada pelo calor, zona fundida) atendam às propriedades requeridas e estejam livres de defeito. As normas atuais de soldagem, como por exemplo a norma AWS D1.1 mantêm em suas tabelas de pré-qualificação procedimentos relacionados a design antigos, como por exemplo, o aço ASTM A572 Grau 65 com carbono máximo de 0,26 $\%$ para chapas com espessura menores que $13 \mathrm{~mm}$, e 0,23 \%, para chapas entre 13 e $32 \mathrm{~mm}$ de espessura.

A zona afetada pelo calor, como descrito por Adonyi [4], apresenta uma mistura complexa de microestruturas em um volume muito pequeno. Desta forma, a propriedade de uma única microestrutura se torna difícil de medir em uma solda real, sendo, portanto, a previsão de onde ela deverá falhar em serviço difícil de ser feita. Assim, o uso de simulações físicas é uma alternativa, por possibilitar estudar regiões as ZAC através de volumes maiores.

Desta forma, o objetivo deste trabalho é estabelece uma metodologia de criação de atlas microestrutural, aplicado a um caso de aço bainítico microligado ao nióbio da classe $65 \mathrm{ksi}$ (aço Sincron da USIMINAS). A partir deste atlas é possível comparar soldas reais com as microestruturas prevendo a resistência mecânica, tenacidade e dureza na zona de região de grãos grosseiros. A estimativa da adequação e otimização de procedimentos de soldagem passa a ser uma realidade com ganhos econômicos e de processo. 


\section{MATERIAIS E MÉTODOS}

\subsection{Caracterização do aço usado no estudo de caso}

O aço Sincron (nome comercial) trata-se de um material produzido por processo TMCP pela USIMINAS, com estrutura basicamente composta de bainita, perlita fina e ferrita poligonal (figura 1). Este aço bainítico tem como base o uso otimizado de microligantes, rota termomecânica durante a laminação e resfriamento rápido após último passe, para obtenção de resistência mecânica a partir da microestrutura refinada e bainítica. As suas características químicas e mecânicas estão descritas nas tabelas 1 e 2.

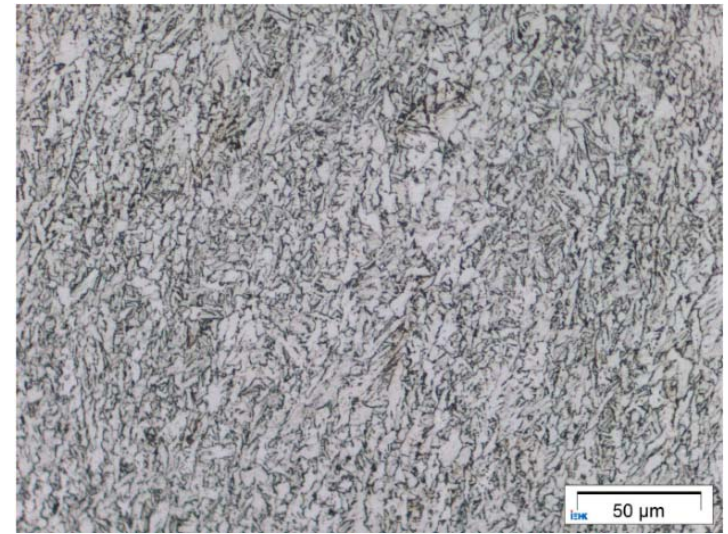

Figura 1: Microestrutura do Aço Sincron (ataque com Nital 4\%)

Tabela 1. Composição Química de Certificado do Aço Sincron (\%)Utilizado no Estudo de Caso

\begin{tabular}{cccccccccc}
\hline $\mathbf{C}$ & $\mathbf{S i}$ & $\mathbf{M n}$ & $\mathbf{P}$ & $\mathbf{S}$ & $\mathbf{N b}$ & $\mathbf{C u}$ & $\mathbf{N}$ & $\mathbf{T i}$ & $\mathbf{C e q}$ \\
\hline 0,09 & 0,25 & 1,50 & 0,014 & 0,002 & 0,030 & 0,143 & 0,004 & 0,013 & 0,35
\end{tabular}

Ceq = carbono equivalente segundo equação do IIW

Tabela 2. Propriedades Mecânicas de Certificado do Aço Sincron Utilizado no Estudo de Caso

\begin{tabular}{cccc}
\hline LE (MPa) & LR (MPa) & Al (\%) & Charpy $\left(-50{ }^{\circ} \mathrm{C}\right)(\mathrm{J})$ \\
\hline 503 & 615 & 22 & 215 \\
\hline
\end{tabular}

Barbaro et al. [5] confirmam que o controle das propriedades da ZAC pode ser realizado através do controle químico da composição do aço. Sendo que uma relação estequiométrica entre titânio e nitrogênio $(\mathrm{Ti} / \mathrm{N})$ provê uma boa homogeneidade e uma grande quantidade de precipitados de nitretos de titânio (TiN) de pequena dimensão, a condição ótima para o efeito de "pinning" que evita o crescimento do grão austenítico. O nióbio atuará no:

- Refinamento de grão;

- Redução da temperatura de transformação entre austenita-ferrita;

- Endurecimento por precipitação;

- Retardamento da recristalização da austenita.

Barbaro et al. [5] citam também que nos aços microligados ao nióbio e titânio existem precipitados complexos de $(\mathrm{Ti}, \mathrm{Nb})(\mathrm{C}, \mathrm{N})$, alguns com núcleos ricos em titânio e camadas externas ricas em nióbio e outros como precipitados isolados. Mesmo sendo conhecido que os precipitados de nióbio nesses aços dissolvem-se a temperaturas mais baixas do que os TiN, percebe-se um melhor controle do crescimento dos grãos 
austeníticos à $1350^{\circ} \mathrm{C}$ nos aços com alto teor de $\mathrm{Nb}$. Os mecanismos para tal podem estar relacionados, mas não limitado, a:

- Efeito de dragagem do $\mathrm{Nb}$ em solução sólida, provindo da dissolução de $\mathrm{NbC}$ e $\mathrm{NbCN}$;

- Existência de camadas ricas de $\mathrm{Nb}$ em torno de $\mathrm{TiN}$, evitando o crescimento dos precipitados de titânio;

- Segregação de $\mathrm{Nb}$ nos contornos dos grãos austeníticos e/ou redução de energia no contorno, o que pode retardar o crescimento do grão.

Ainda, na descrição de Barbaro et al.[5], o molibdênio também tem efeitos benéficos, mas que ainda não foram completamente mensurados ou estudados.

Stalheim \& Muralidharan [6] demonstram em seu trabalho de simulação de diferentes curvas CCT (ou TTT contínuo) que os diferentes elementos afetam as transformações de fase de maneira diferente nos aços para tubulações de petróleo e gás. Como exemplo, um aumento do teor de carbono move o campo ferrítico, perlítico e bainítico para a direita (aumentando o tempo necessário para a transformação) permitindo a formação da fase martensítica. Já a adição de elementos como molibdênio, níquel e nióbio reduzem a cinética de formação da ferrita e perlita permitindo desta forma uma maior formação de bainita. Cada elemento afeta o diagrama CCT diferentemente, seja na natureza ou na magnitude.

Scotti et al. [7], entretanto, alertam que aços estruturais com tratamento termomecânico apresentam alguns cuidados e, por isso, existe a necessidade do estudo do seu comportamento durante os ciclos térmicos de soldagem, que no caso deste trabalho foi realizado através de simulação física da ZAC.

\subsection{Simulação física da ZAC}

Stalheim \& Muralidharan [6] citam que as propriedades mecânicas de um aço são função das frações volumétricas das fases na microestrutura e sua respectiva morfologia e que curvas CCT têm sido utilizadas como forma de selecionar composições e rotas de processo apropriadas, de forma a obter uma microestrutura específica desejável de maneira também efetiva em custos.

Normalmente, os diagramas CCT são desenvolvidos em condições laboratoriais, requerendo um extenso tempo e esforço técnico. Uma das formas mais simples de obter esses diagramas de forma experimental são através de simulações térmicas (conhecidas também como simulações físicas), nas quais pequenas amostras são submetidas a ciclos térmicos similares aos experimentados pelo material, por exemplo, durante soldagem. Scotti et al. [7] mostram que simulações térmicas têm sido amplamente utilizadas para a avaliação da zona afetada pelo calor. Entretanto, esses autores descrevem que nas simulações laboratoriais parâmetros chaves vêm sendo adotados de forma independente e desiguais, pela falta de literatura comparativa ou por resultados disponibilizados pelos autores de forma incompleta. Outra diferenciação é devido a limitações dos equipamentos. A tabela 3 demonstra alguns exemplos comparativos de tais diferenças. 
Tabela 3 - Comparação entre Métodos de Simulação Térmica (Scotti et al.[7])

\begin{tabular}{ccccc}
\hline Equipamento & $\begin{array}{c}\text { Taxa de } \\
\text { Aquecimento } \\
\left({ }^{\circ} \mathbf{C} / \mathbf{s}\right)\end{array}$ & $\begin{array}{c}\text { Temperatura } \\
\text { de pico }\left({ }^{\circ} \mathbf{C}\right)\end{array}$ & $\begin{array}{c}\text { Tempo na } \\
\text { temperatura } \\
\text { de pico }(\mathbf{s})\end{array}$ & $\begin{array}{c}\text { Fonte } \\
\text { (referências em } \\
\text { Scotti et al.[7]) }\end{array}$ \\
\hline $\begin{array}{c}\text { Gleeble/ } \\
\text { Dilatômetro }\end{array}$ & 500 & 1000 a 1350 & 1 & Bayraktar \& Kaplan \\
\hline Gleeble & 100 & 1300 & 1 & Caron et al. \\
\hline Dilatômetro & 50 & 1350 & 5 & Kuzmikova et al. \\
\hline Gleeble & 500 & 1350 & 1 & Lane et al. \\
\hline Gleeble & Não disponível & 1350 & 1 & Liou et al. \\
\hline Dilatômetro & 30 & 1150 a 1250 & Não disponível & Loureiro \& \\
\hline Dilatômetro & 40 & 950 a 1250 & 30 & Miranda \& Fortes \\
\hline Dilatômetro & 150 & 1200 & Não disponível & Onsøien et al. \\
\hline Smitweld & 150 & 975 & 0,5 & Samardžić et al. \\
\hline Gleeble & 433 & 1300 & 2 & Shi \& Han \\
\hline Gleeble & 200 & 1000 a 1400 & 0,15 & Shome \& Mohanty \\
\hline Dilatômetro & 100 & 1400 & Não disponível & Spanos et al. \\
\hline Gleeble & 400 & 1350 & 0,5 & Zheng et al.
\end{tabular}

Adonyi [4] ressalta que uma questão fundamental é a correlação entre as microestruturas e propriedades simuladas com os resultados reais, sendo responsável por cerca de 70 a $80 \%$ do tempo consumido nestes projetos. Porém, uma vez encontrada esta correlação, o processo se torna confiável, fácil de usar, com boa repetitividade e eficiente em termos de custo. A tentativa de aplicação direta de uma curva CCT ao processo de soldagem precisa ser cautelosa e comparada com soldas reais.

Assim, o aço em estudo foi simulado em diferentes ciclos térmicos em dilatômetro de altas taxas de resfriamento e Gleeble, conforme detalhado na tabela 4, de forma a complementar as informações para o atlas.

Os ciclos foram escolhidos de forma a caracterizar a região de grãos grosseiros da zona afetada pelo calor (ZAC GG) de uma solda de passe único. Foi utilizada a simulação em dilatômetro para maior precisão e faixa de simulação. O uso do Gleeble se deve a necessidade de correlacionar as microestruturas dos ciclos térmicos com características mecânicas do aço (tenacidade e resistência a tração, por exemplo), o que não é possível na simulação por dilatômetro, devido a reduzida dimensão dos corpos de prova.

Após as simulações, os corpos de prova foram caracterizados quanto a sua microestrutura, dureza, tenacidade (ensaio charpy $\vee$ em diferentes temperaturas) e resistência a tração. Com estes resultados foram estabelecidas as curvas de transformação (CCT), características microestruturais, dureza e características mecânicas (resistência a tração, tenacidade e temperatura de transição díctil-frágil) que compõe o atlas objeto deste artigo. 
Tabela 4. Ciclos Térmicos Simulados para Caracterização da ZAC GG do Aço Sincron

Tempo de manutenção na temperatura de pico (s)
Taxa de

ID aquecimento $\left({ }^{\circ} \mathrm{C} / \mathrm{s}\right)$
Temperatura de pico $\left({ }^{\circ} \mathrm{C}\right)$
Tempo t8/5 Equipamento de (s) simulação

\begin{tabular}{cccccc}
\hline $\mathbf{1}$ & 90 & 1300 & 2 & 0,6 & Dilatômetro \\
\hline $\mathbf{2}$ & 90 & 1300 & 2 & 1,8 & Dilatômetro \\
\hline $\mathbf{3}$ & 90 & 1300 & 2 & 2,6 & Dilatômetro \\
\hline $\mathbf{4}$ & 90 & 1300 & 2 & 4,6 & Gleeble \\
\hline $\mathbf{5}$ & 90 & 1300 & 2 & 6,4 & Dilatômetro \\
\hline $\mathbf{6}$ & 90 & 1300 & 2 & 10,8 & Gleeble \\
\hline $\mathbf{7}$ & 90 & 1300 & 2 & 13,3 & Dilatômetro \\
\hline $\mathbf{8}$ & 90 & 1300 & 2 & 26,1 & Dilatômetro \\
\hline $\mathbf{9}$ & 90 & 1300 & 2 & 27,0 & Gleeble \\
\hline $\mathbf{1 0}$ & 90 & 1300 & 2 & 52,0 & Dilatômetro \\
\hline $\mathbf{1 1}$ & 90 & 1300 & 2 & 72,0 & Gleeble \\
\hline $\mathbf{1 2}$ & 90 & 1300 & 2 & 104,0 & Dilatômetro \\
\hline $\mathbf{1 3}$ & 90 & 1300 & 2 & 208,0 & Dilatômetro \\
\hline $\mathbf{1 4}$ & 90 & 1300 & 2 & 416,0 & Dilatômetro \\
\hline $\mathbf{1 5}$ & 90 & 1300 & 2 & 832,0 & Dilatômetro \\
\hline $\mathbf{1 6}$ & 90 & 1300 & 2 & 1680,0 & Dilatômetro \\
\hline
\end{tabular}

\section{RESULTADOS E DISCUSSÃO}

Primeiramente, foi realizado a comparação entre as simulações em Dilatômetro e Gleeble de forma a avaliar a sua equivalência. Foram utilizadas as características de dureza e a microestrutura, representadas nas Figura 2 e Tabela 5, que demonstram que não houve influência do método de simulação no resultado final das amostras simuladas.

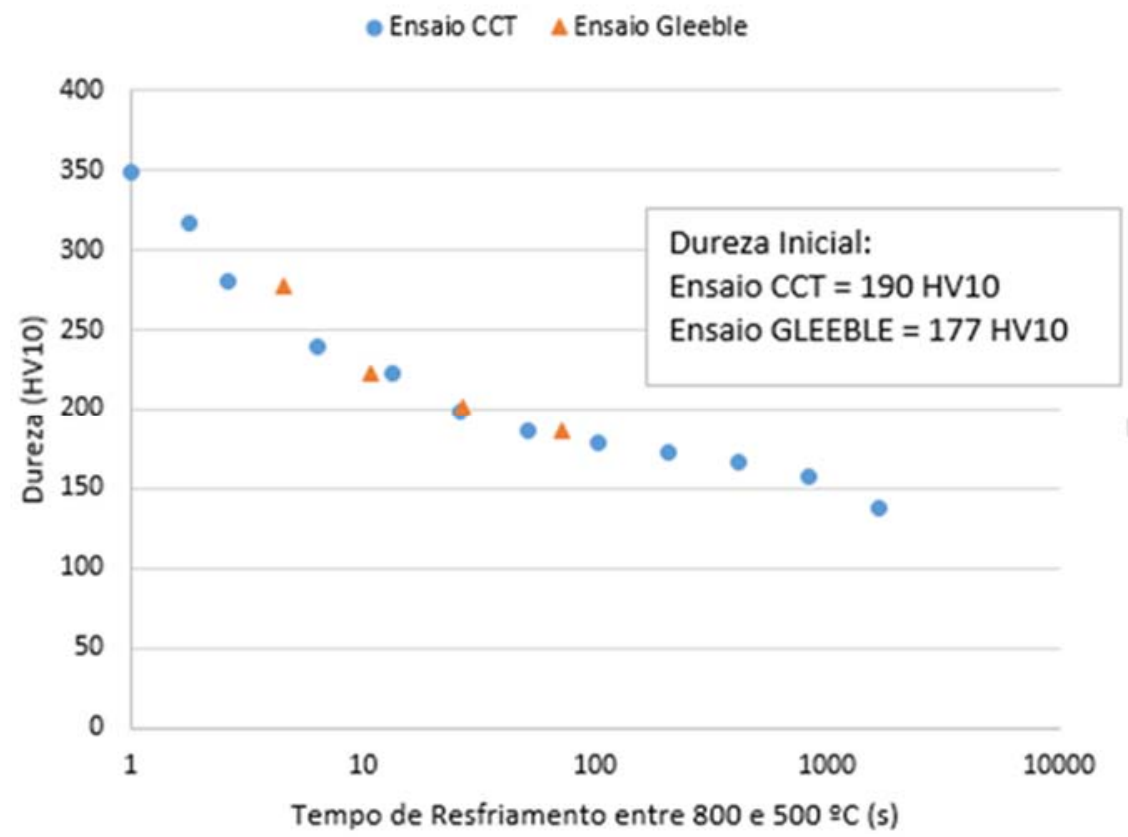

Figura 2: Comparativo de Dureza entre as Amostras Simuladas em Dilatômetro e Gleeble 
Tabela 5: Similaridade entre Microestruturas de Ensaios em Equipamentos Diferentes Ensaio Dilatômetro

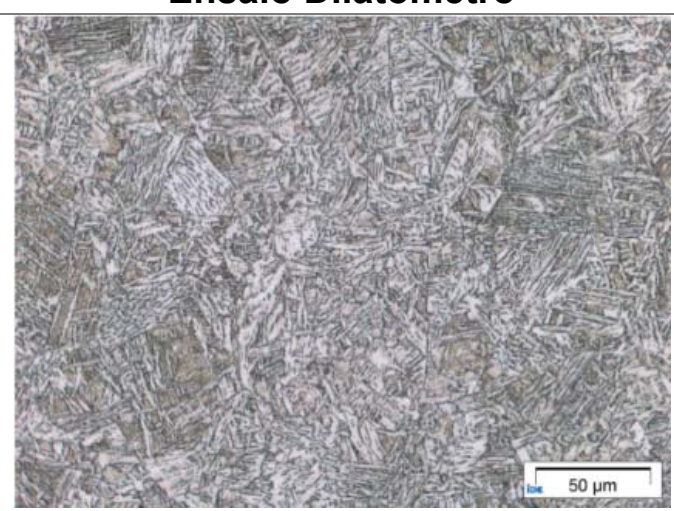

$\mathrm{t} 8 / 5=6,4 \mathrm{~s}$

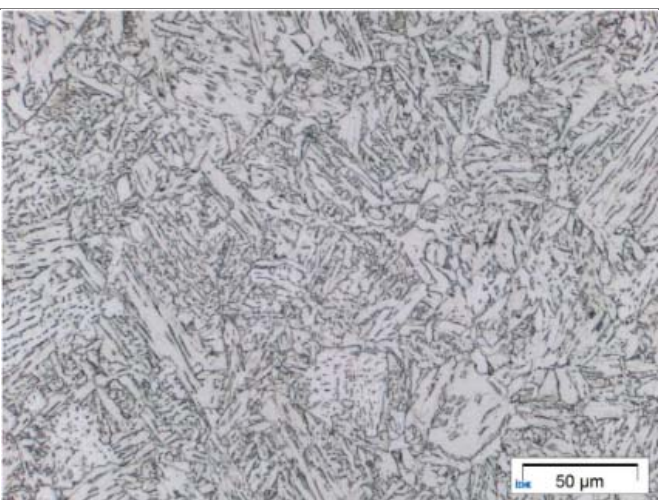

$\mathrm{t} 8 / 5=26,1 \mathrm{~s}$

\section{Ensaio Gleeble}

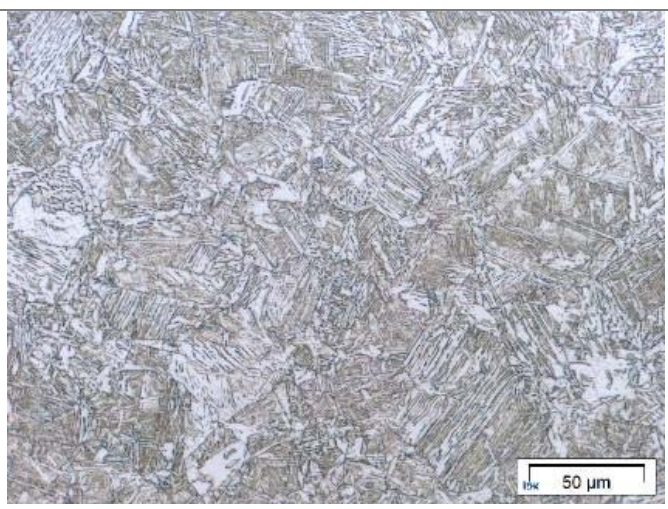

$\mathrm{t} 8 / 5=4,6 \mathrm{~s}$

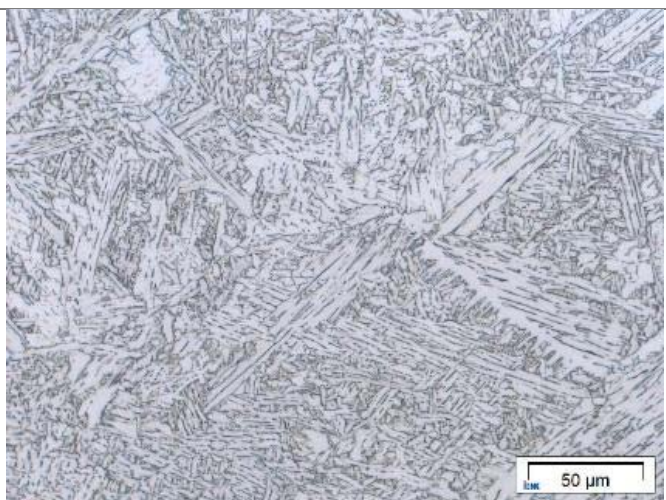

$\mathrm{t} 8 / 5=27 \mathrm{~s}$

Com base na metodologia descrita, foi desenvolvido o atlas microestrutural representado pela figura 3 e tabela 6.

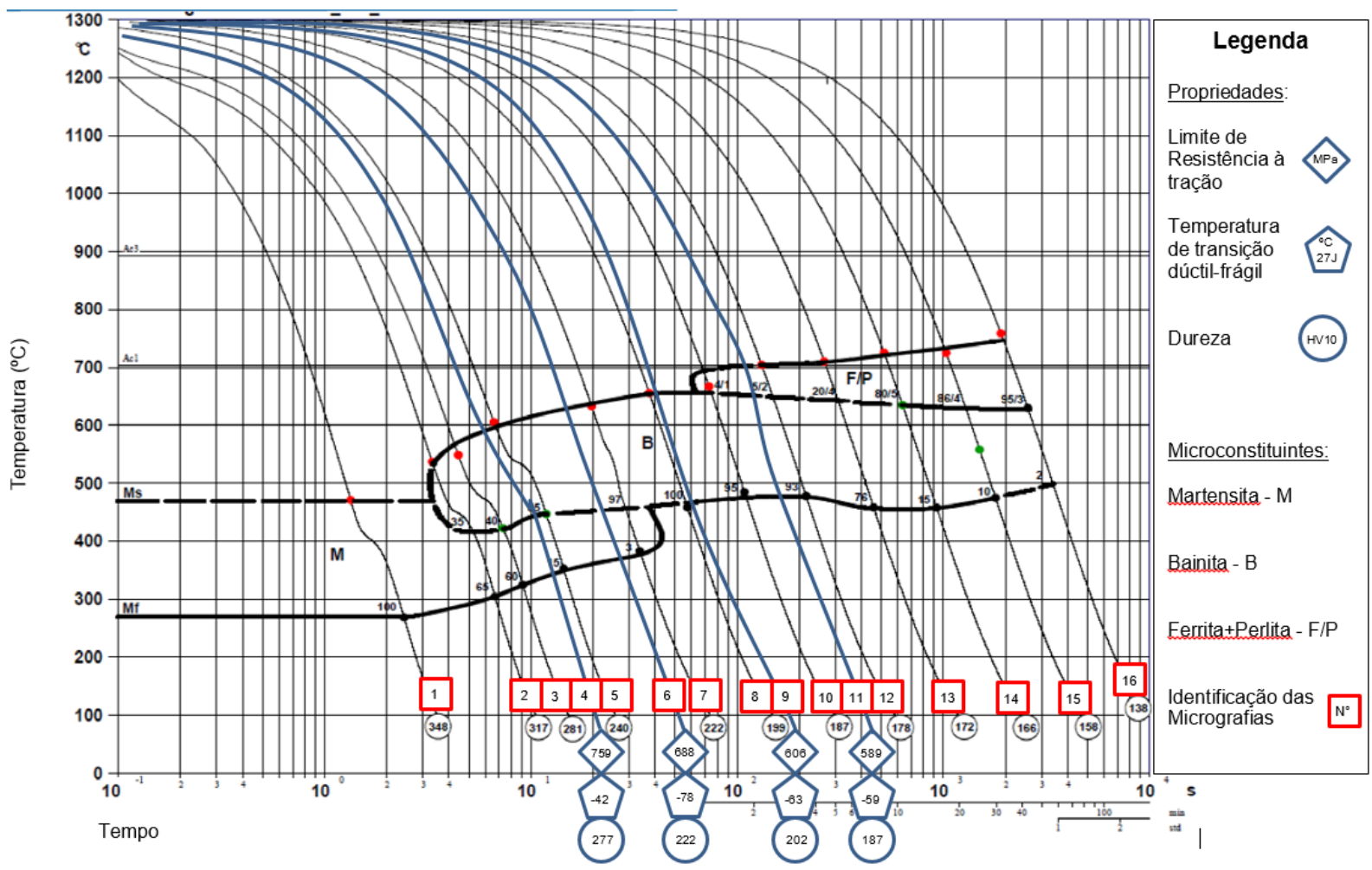

Figura 3: Atlas do Aço Sincron 
Tabela 6: Microestruturas do Atlas do Aço Sincron (apenas algumas microestruturas selecionadas para exemplificação)

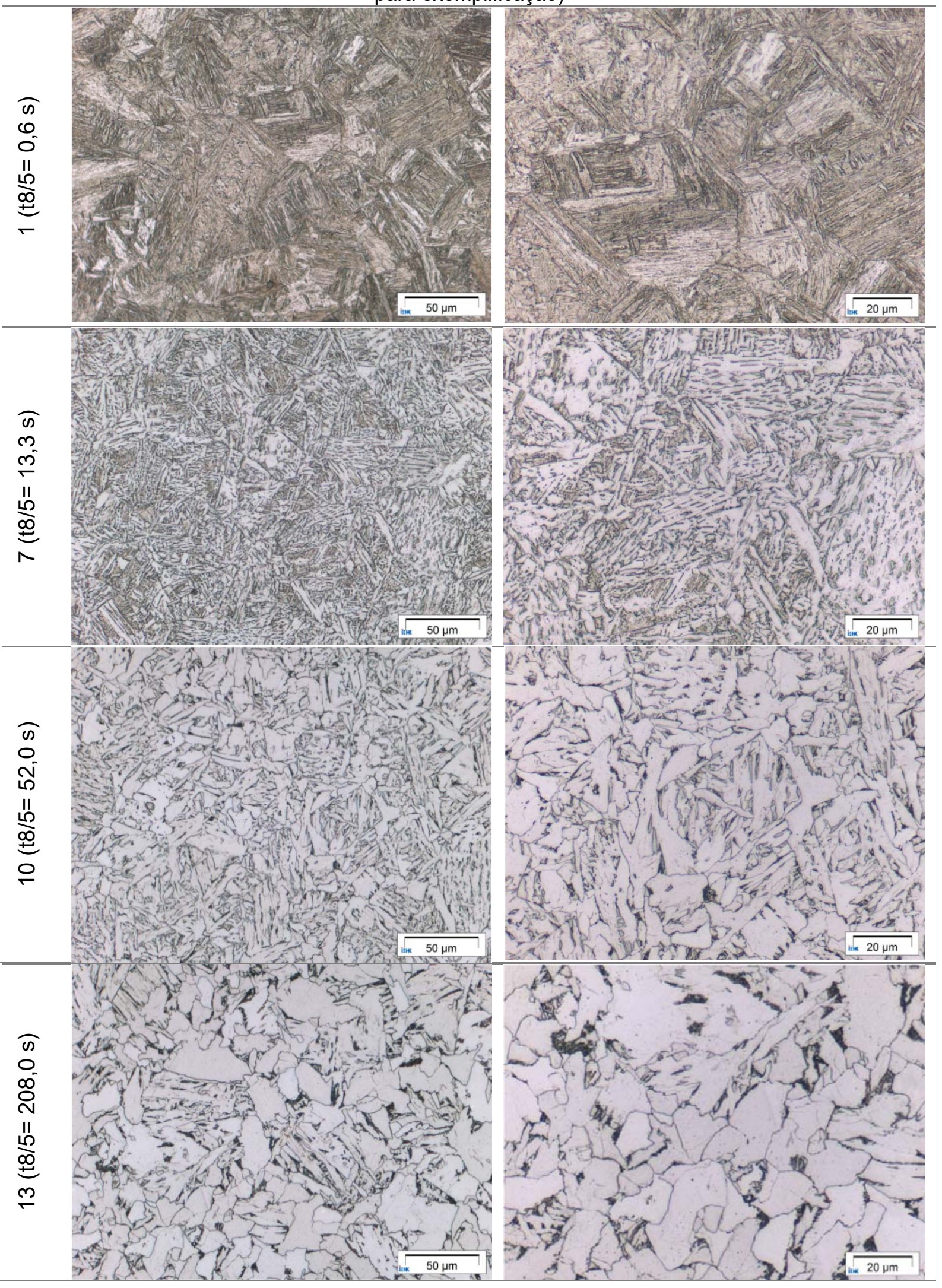

A partir deste atlas é possível comparar soldas reais com as microestruturas prevendo a resistência mecânica, tenacidade e dureza na zona de região de grãos grosseiros. A estimativa da adequação e otimização de procedimentos de soldagem passa a ser 
uma realidade através de uma ferramenta simples que é a análise microestrutural de soldas reais realizadas em placas de teste.

\subsection{Comparação com solda real}

Foi realizada uma comparação com duas soldas realizadas pelo processo SAW, com e sem pré-aquecimento, de forma a avaliar a necessidade de pré-aquecimento e as consequências em termos estruturais da não utilização do mesmo. A figura 4 demonstra o comparativo das microestruturas das soldas reais e as do atlas.

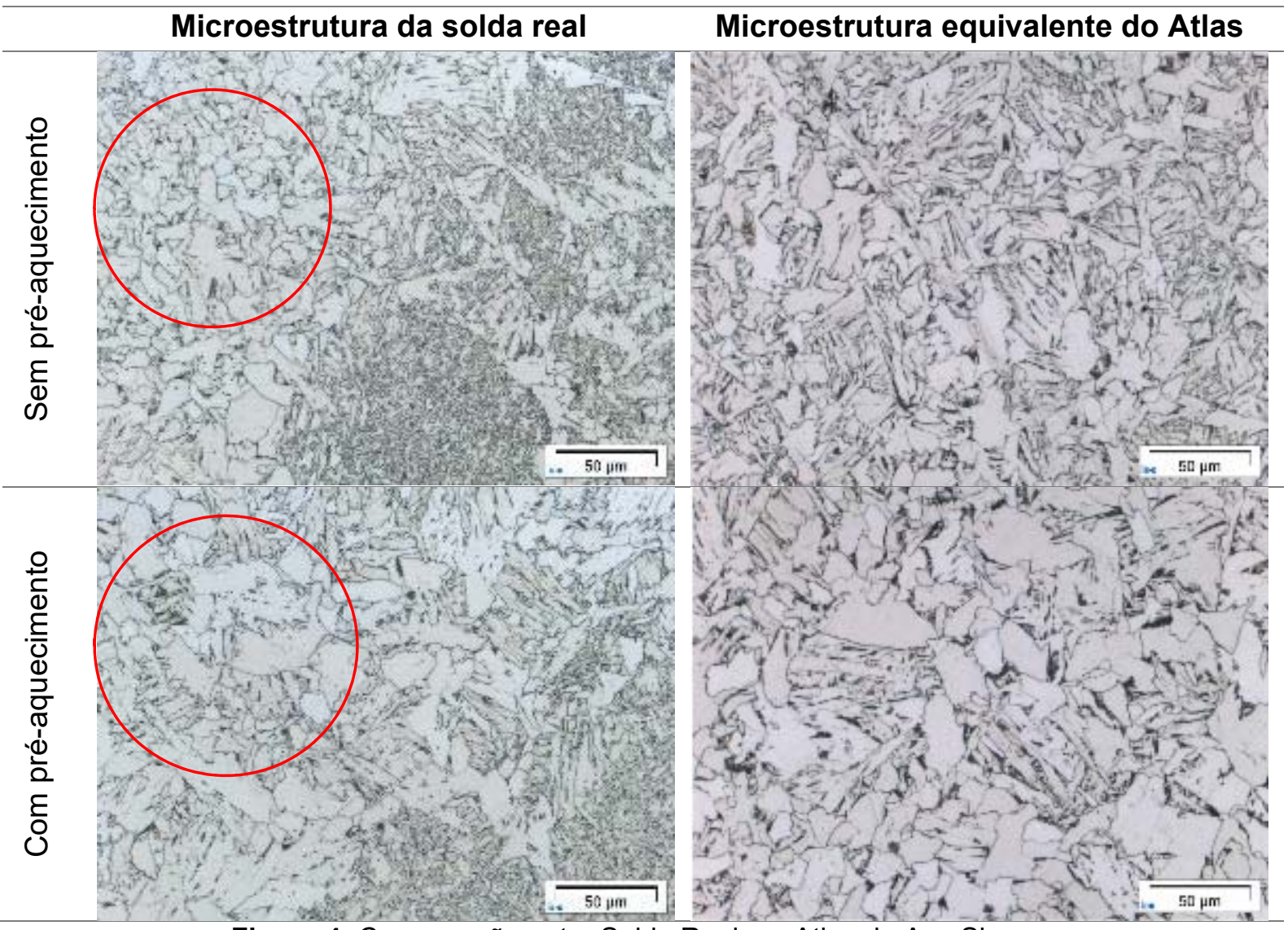

Figura 4: Comparação entre Solda Real e o Atlas do Aço Sincron

Estima-se pela comparação com o atlas que o t8/5 passou de cerca de 100s (estrutura 12) quando soldado sem pré-aquecimento para cerca de 200 s (estrutura 13) quando soldado com pré-aquecimento, mostrando o efeito do pré-aquecimento na redução da velocidade de resfriamento da ZAC GC, como esperado, mas agora quantificado.

Entretanto, observando-se o Atlas, verifica-se que as durezas para a condição sem pré-aquecimento e com pré-aquecimento foram equivalentes sem alteração quanto aos riscos de trinca por aparecimento de fases frágeis. Além disto, quanto às propriedades mecânicas, observou-se que a energia absorvida no impacto em charpy $V$, a resistência a tração e a temperatura de transição se mostraram equivalentes, 0 que pode ser associado a um envelope de soldabilidade que resulta em estrutura majoritariamente bainítica, não afetando novamente o atendimento as propriedades requeridas para o material. Desta forma, o uso do pré-aquecimento para este aço parece ser desnecessário, apesar de indicado pela norma AWS D1.1.

Através da eliminação do procedimento pré-aquecimento em soldagem, foi realizada a estimativa de economia em um projeto de prédio de estrutura metálica com cerca 
de 21850 metros de solda linear pelo processo SAW. Houve uma redução de custo de fabricação de aproximadamente $\mathrm{R} \$ 732$ mil em oxigênio e GLP, além de uma economia de 6,77 TJ (tera joule) de energia e uma redução de emissão de gases de efeito estufa de 427,6 toneladas de carbono equivalente. Estes valores foram calculados com base nos consumos de uma fábrica de produção de estruturas metálicas e dados do IPCC.

\section{CONCLUSÃO}

A aplicação do Atlas no caso do aço Sincron (ASTM A572 Grau 65) mostrou que não haveria necessidade do uso de pré-aquecimento para evitar microestruturas frágeis e susceptíveis a trincas de hidrogênio. Mostrou também que no caso de se desejar maiores tenacidades na região de grãos grosseiros da ZAC, outros parâmetros de soldagem poderiam ter sido especificados para se obter velocidades de resfriamento maiores, já que o Atlas mostrou que o aço em estudo tem um amplo envelope de soldabilidade. Desta forma, conclui-se que é possível, pelo uso do atlas, aumentar a confiabilidade da resposta metalúrgica dos parâmetros de soldagem selecionados em elaboração de EPS (Especificação de Procedimento de Soldagem) para aços estruturais e, assim, tornar as EPS menos conservativas e mais econômicas.

\section{Agradecimentos}

Agradecemos as empresas CODEME, USIMINAS, IWT e ao Programa de Pósgraduação em Engenharia Mecânica da UFU pela parceria neste projeto.

\section{REFERÊNCIAS}

1 Meester B. The Weldability of Modern Structural TMCP Steels. ISIJ International. 1997; 37 (6):537-551.

2 Fluess $\mathrm{P}$, Valentin R, Schwinn V, Hanus F. Application of Nb in TMCP Structural Steel Plates with Thickness up to 120 mm. Niobium Bearing Structural Steels - TMS. 2010; 89-103.

3 Lan L, et al. Microstructural Characteristics and Toughness of the Simulated Coarse Grained Heat Affected Zone of High Strength Low Carbon Bainitic Steel. Materials Science and Engineering - Elsevier. 2011: A 529; 192-200.

4 Adonyi Y. Heat-Affected Zone Chatacterization by Physical Simulations. Welding Journal. 2011: Oct.; 42-47.

5 Barbaro F, J.; Zhu, Z.; Kuzmikova, L.; Li, H.; Gray, J. M. Towards Improved Steel Alloy Designs for Controlo f Weld Heat Affected Zone Properties. 2nd International Symposium on $\mathrm{Nb}$ and Mo Alloying in High Performance Steels.2013; 1-13.

6 Stalheim D G, Muralidharan G. The Role of Continuous Cooling Transformation Diagrams in Material Design for High Strength Oil and Gas Transmission Pipeline Steels. Proceedings of IPC 2006, 6th International Pipeline Conference, Calgary. 2006.

7 Scotti A, Li H, Miranda R M. Um Round-Robin Teste com Simulação Térmica da ZAC de Soldagem para Obtenção de Diagramas CRC: A Necessidade de Procedimentos e Terminologia de Microconstituintes Harmonizados. Soldagem e Inspeção. 2014; 19 (03): 279-290. 